\title{
Psykogene ikke-epileptiske anfall hos barn
}

\author{
Psykogene ikke-epileptiske anfall er anfall av epilepsilignende karakter \\ som ikke har et hjerneorganisk korrelat. Som navnet indikerer, antar \\ man at psykologiske prosesser spiller en rolle. Vårt inntrykk ved Spe- \\ sialsykehuset for epilepsi er at forekomsten av slike anfall blant barn \\ og unge har økt de siste årene.
}

Psykogene ikke-epileptiske anfall, i internasjonal litteratur gjerne forkortet PNES (psychogenic non-epileptic seizures), er som den viktigste differensialdiagnosen til epilepsi godt kjent i voksennevrologien og er tidligere omtalt i Tidsskriftet $(1,2)$. Vårt inntrykk er at slike anfall er mindre kjent blant pediatere, skoleleger og fastleger.

Man antar at psykogene ikke-epileptiske anfall hovedsakelig er et symptom på en konversjonslidelse $(3,4)$. I diagnoseklassifikasjonssystemene DSM-5 og ICD-10 blir tilstanden kategorisert som henholdsvis en konversjons- og dissosiasjonstilstand. I motsetning til i ICD-10 kreves det ikke at man har holdepunkter for en psykisk årsak for å sette diagnosen i det nylig reviderte amerikanske DSM-5. Klinisk kan det, særlig i den første utredningsfasen, være vanskelig å oppdage bakenforliggende psykiske belastninger.

Anfallene ses noe sjeldnere hos barn enn hos voksne (5). De er imidlertid en stor belastning ikke bare for den det gjelder, men også for familie, skole og samfunn. Barna er ofte gjenstand for gjentatte akuttinnleggelser og mange unødvendige undersøkelser. Mange får dessuten etter hvert et stort forbruk av lite virksomme legemidler (4).

Psykogene ikke-epileptiske anfall hos barn skiller seg fra slike anfall hos voksne på flere måter, blant annet er de bakenforliggende årsakene $(3,6-8)$, anfallsutformingen $(9,10)$ og prognosen noe forskjellig $(11)$.

Hensikten med denne artikkelen er å gi en kort oversikt over forekomst, risikofaktorer, ytringsformer, diagnostikk og behandling av slike anfall hos barn. Artikkelen er basert på søk i PubMed med søkeordet «psychogenic non-epileptic seizures» og forfatternes kliniske erfaring.

\section{Forekomst}

Den eksakte prevalensen av psykogene ikkeepileptiske anfall blant barn er ikke kjent (5). Første anfall opptrer som oftest i 8-15-årsalderen $(10,12,13)$, men diagnostiseringen er gjerne forsinket $(10,14)$. Tilstanden er sett hos barn helt ned til 4-5-årsalderen.

Hos barn hvor man mistenker epilepsi, er prevalensen av psykogene ikke-epileptiske anfall funnet å være $5-13 \%(5,15)$. I mate- rialer bestående av barn henvist til videoEEG for en diagnostisk utredning av forskjellige typer anfall, har man funnet tilstanden hos 3,5-20\% $(12,16,17)$. Blant barn henvist til pediatriske epilepsisentra for intraktabel epilepsi er det funnet en forekomst av barn med slike anfall på $10-23 \%(8,18)$.

Blant ungdom og voksne med tilstanden er 70-80\% kvinner $(4,19,20)$. Kjønnsforskjellen er ikke så uttalt blant barn (18).

Som hos voksne er det ikke helt uvanlig at psykogene ikke-epileptiske anfall koeksisterer med epilepsi (18). Men hvor ofte en blanding av begge anfallsformer forekommer, er usikkert og angis svært forskjellig (21).

\section{Risikofaktorer}

Psykogene ikke-epileptiske anfall ses på som et symptom på underliggende kroniske konflikter eller stressorer (22). Oppvekst i en dysfunksjonell familie, faglige vansker på skolen, mobbing eller andre problemer i kameratflokken er hyppig assosiert med tilstanden hos barn $(4,22)$. Fysisk eller seksuelt misbruk er ikke like vanlig blant barn med slike anfall som hos voksne (23), selv om en studie viste at $21 \%$ og $6 \%$ hadde opplevd henholdsvis seksuelt eller fysisk misbruk (3).

I en kontrollert studie ble 55 barn med psykogene ikke-epileptiske anfall sammenlignet med sine søsken (4). Gjennomsnittsalderen var 14,3 år, og $71 \%$ var jenter. Man fant at alle barna hadde en konversjonslidelse. Sammenlignet med kontrollgruppene hadde de en signifikant økt nevrologisk (inkludert epilepsi), medisinsk og psykiatrisk morbiditet, økt medisinbruk, hyppigere intensivbehandling, en innadvendt mestringsstrategi, flere skolevansker, mer skolefravær, de var mer utsatt for mobbing, og de hadde større interpersonlige problemer (4).

I en spørreundersøkelse blant danske barnenevrologer var det en alminnelig oppfatning at slike anfall var assosiert med stress, fysiske og/eller psykiske traumer og seksuelt misbruk (24).

Personlighetstester har vist at mange barn med slike anfall har et høyt spenningsnivå med mye angst, depresjon og mistilpassede personlighetstrekk (24). Opptil en tredel av

\author{
Morten I. Lossius \\ mortenl@ous-hf.no \\ Antonia Villagran \\ Hilde N. Karterud \\ Oliver Henning \\ Karl O. Nakken \\ Spesialsykehuset for epilepsi (SSE) \\ Nevroklinikken \\ Oslo universitetssykehus
}

\section{HOVEDBUDSKAP}

Psykogene ikke-epileptiske anfall hos barn blir ofte forvekslet med genuine epileptiske anfall

Psykogene ikke-epileptiske anfall er svært belastende for så vel pasient som pårørende og kan legge beslag på mye ressurser i helsevesenet

Hos barna ytrer anfallene seg noe annerledes enn hos voksne

Prognosen er bedre hos barn enn hos voksne 
Tabell 1 Noen forskjeller mellom psykogene ikke-epileptiske anfall hos barn og hos voksne og genuine epileptiske anfall. Tabellen er dels basert på egne erfaringer og dels på sentrale artikler fra området, bl.a. Alessi og medarbeidere (9)

\begin{tabular}{|c|c|c|c|}
\hline & $\begin{array}{l}\text { Psykogene ikke-epileptiske } \\
\text { anfall hos barn }\end{array}$ & $\begin{array}{l}\text { Psykogene ikke-epileptiske } \\
\text { anfall hos voksne }\end{array}$ & Genuine epileptiske anfall \\
\hline Anfallsutforming & $\begin{array}{l}\text { Ofte «stille» anfall, manglende } \\
\text { kontakt }\end{array}$ & $\begin{array}{l}\text { Ofte dramatiske anfall med moto- } \\
\text { risk uro, asynkrone rykninger, } \\
\text { eventuelt opistotonus }\end{array}$ & $\begin{array}{l}\text { Mange typer anfall - fra absenser } \\
\text { til tonisk-kloniske anfall }\end{array}$ \\
\hline $\begin{array}{l}\text { Varierende intensitet av anfallet } \\
\text { underveis }\end{array}$ & Vanlig & Vanlig & Sjelden \\
\hline Hodebevegelser fra side til side & Vanlig & Vanlig & Sjelden \\
\hline $\begin{array}{l}\text { Motstand mot passive bevegelser, } \\
\text { inkludert øyelokk }\end{array}$ & Vanlig & Vanlig & Sjelden \\
\hline Lukkede øyne under anfallet & Vanlig & Vanlig & Sjelden \\
\hline Gråt under anfallet & Forekommer & Forekommer & Sjelden \\
\hline Rask oppvåkning etter anfallet & Vanlig & Vanlig & Sjelden \\
\hline Nattlige anfall & Svært sjelden & Svært sjelden & $\begin{array}{l}\text { Forekommer, avhengig av epilepsi- } \\
\text { formen }\end{array}$ \\
\hline Anfallsvarighet & Som oftest mer enn to minutter & Som oftest mer enn to minutter & Som oftest mindre enn to minutter \\
\hline Effekt av antiepileptika & Ingen & Ingen & Som oftest god \\
\hline Iktale EEG-funn & Ingen epileptiform aktivitet & Ingen epileptiform aktivitet & Som regel epileptiform aktivitet \\
\hline Anfallsprognose & Som regel god & $\begin{array}{l}\text { Varierende, men dårligere enn } \\
\text { hos barn }\end{array}$ & Avhengig av epilepsiform \\
\hline
\end{tabular}

barna har en forsinket psykomotorisk utvikling (21).

\section{Anfallsutforming}

Det er funnet interessante forskjeller i anfallssemiologien, dvs. hvordan anfallene ytrer seg klinisk, mellom barn og voksne $(8-10,12$, $19,24)$. Anfallene hos barna er gjerne «fredeligere» og mer stereotype enn hos voksne. Hos voksne ses ofte lukkede øyne, voldsomme bevegelser, vokalisering og opistotonus. Anfallene hos barn er ofte av dialektisk art, dvs. at de ytrer seg ved langvarig kontaktløshet. Er det motoriske symptomer, dreier det seg oftest om tremor eller grove, asynkrone bevegelser av ekstremitetene samt et fluktuerende forløp (22). Når barna kommer i puberteten, blir anfallsutformingen mer lik den som man ser hos voksne. Anfallene starter og slutter gjerne abrupt (21).

Som hos voksne varer anfallene lenger enn de epileptiske anfallene. En pediatrisk studie viste en gjennomsnittlig varighet av psykogene ikke-epileptiske anfall på 269 sekunder mot 83 sekunder for epileptiske anfall (12).

Ifølge danske barnenevrologer er typiske trekk hos barn med slike anfall lukkede øyne, motstand mot å åpne øynene, sjelden anfallsrelaterte skader, anfallene kommer som oftest i sosiale settinger, fravær av postiktale symptomer og manglende effekt av antiepileptiske legemidler (24).
I tabell 1 kan man se noen forskjeller mellom psykogene ikke-epileptiske anfall hos barn, psykogene ikke-epileptiske anfall hos voksne og epileptiske anfall.

\section{Diagnostikk}

Alle barn med hyppige epilepsilignende anfall til tross for behandling, anfall som for epilepsi er atypiske når det gjelder ytringsform og varighet, samt flere normale EEG, bør vekke mistanke om psykogene ikke-epileptiske anfall (21).

Det finnes ingen internasjonale retningslinjer for diagnostikk og behandling av slike anfall hos barn (24). Mange av barna får epilepsidiagnose og årelang behandling med antiepileptika. I en studie fra India var det tilfelle hos 33 av 56 barn med slike anfall (10). De som først får epilepsidiagnose, har gjerne lært at anfallene resulterer i økt oppmerksomhet, noe som kan vedlikeholde anfallstendensen.

En spørreundersøkelse blant danske barnenevrologer viste ingen enighet verken når det gjaldt terminologi eller kodebruk. Kun $49 \%$ av barnenevrologene anga at de brukte video-EEG i diagnostikken (25).

Etter vårt skjønn bør diagnostikken av slike anfall hovedsakelig bygge på en grundig sykehistorie, inkludert komparentopplysninger, med nøyaktig kartlegging av omstendighetene rundt anfallsopptredenen, selve anfallsutformingen og registrering av typiske anfall på video-EEG. Det bør være holdepunkter for at pasienten har emosjonelle belastninger som kan forklare utviklingen av anfallene, selv om dette altså ikke er obligatorisk ifølge DSM-5.

Spesialsykehuset for epilepsi har landsfunksjon for diagnostisering og initial oppfølging av barn og voksne med psykogene ikkeepileptiske anfall. Alle pasienter med epilepsilignende anfall av uklar natur kan henvises til et kartleggingsopphold ved sykehuset.

I det første oppholdet inngår en grundig anamnese med særlig oppmerksomhet rettet mot barnets psykososiale miljø, omstendighetene rundt anfallene og selve anfallsutformingen. I tillegg foretas langtids video-EEG med målsetting om å registrere anfallene. Dersom anfallene ikke har EEG-korrelat, og sykehistorie og anfallssemiologi gir mistanke om psykogene ikke-epileptiske anfall, er vi rimelig sikre på anfallenes natur.

Det er imidlertid viktig å understreke at man ikke kan bygge diagnosen på manglende iktalt EEG-korrelat alene. Det finnes nemlig flere typer epileptiske anfall, særlig utgående fra frontallappen, der man ikke finner slikt korrelat (26).

\section{Behandling}

Generelt bør behandlingen være rettet mot det man i hvert tilfelle antar ligger til grunn for anfallene. Både hos voksne og barn har psyko- 
edukasjon, stressreduserende tiltak samt læring av avspenningsteknikker og fysioterapi vist seg effektivt (27). Mange har nytte av å lære bedre og mer adekvate mestringsstrategier. I noen tilfeller kan familieterapi, kognitiv terapi og støttebehandling være indisert (27).

Dersom barnet bruker antiepileptiske legemidler bør disse trappes gradvis ned til full seponering. I tilfeller der det foreligger en blanding av epileptiske og psykogene ikkeepileptiske anfall kan det være aktuelt å forenkle medikasjonen fordi mange av disse etter hvert får en omfattende multifarmasi.

Under det andre oppholdet ved Spesialsykehuset for epilepsi bearbeides barnets og pårørendes reaksjon på diagnosen av et spesialtrenet team. Det blir foretatt en tverrfaglig kartlegging av barnets psykisk helse, trivsel i hjem og skole og skoleprestasjoner. Den psykiske helsen kartlegges ved hjelp av spørreskjemaer, og de kognitive evnene måles av spesialpedagog i samarbeid med nevropsykolog. Mot slutten av oppholdet arrangeres det en videokonferanse med barnets lokale hjelpeapparat med tanke på informasjonsoverføring og råd om videre behandling samt takling av eventuelle fremtidige anfall. Avdekker man symptomer på psykisk sykdom, henvises pasienten til lokal barne- og ungdomspsykiatrisk poliklinikk.

Dersom det har vært mye dramatikk på barnets skole i forbindelse med anfallene og mange akuttinnleggelser på sykehus, besøker deler av teamet skolen for å trygge lærere og eventuelt medelever. Dersom barnet har et høyt stressnivå på grunn av faglig tilkortkomming, kan det være aktuelt med spesielt tilrettelagt undervisning.

Barn og unge med slike anfall føler seg ofte stigmatisert og mistrodd (28). Noen opplever dette så vanskelig at de trekker seg tilbake sosialt, eller de blir overbeskyttet av foreldrene. Dersom ungdommene selv har en god sykdomsforståelse, er det lettere å håndtere reaksjonene fra omgivelsene. Det er derfor viktig å bruke god tid på formidling av diagnosen. Dette bør gjøres på en empatisk og ikke-konfronterende måte. Diskusjoner om de mulige underliggende mekanismene ved slike anfall er helt essensielt for barnas mestring (28). Vi benytter en biopsykososial forklaringsmodell som bygger på en forståelse av at både psykososiale og biologiske forhold kan være predisponerende, utløsende og vedlikeholdende faktorer. En slik forklaring kan gjøre det enklere for barna selv å forstå hvorfor de har utviklet anfall og å identifisere seg med diagnosen (29).

For noen barn og pårørende oppleves det som en lettelse å høre at anfallene ikke er ledd i en hjerneorganisk sykdom som krever årelang medisinering, og at anfallene opptrer ubevisst, dvs. at de ikke er viljestyrte.

De sammensatte problemene som ofte ligger bak slike anfall, fordrer en multidisi- plinær tilnærming (13). Vi søker å oppnå en terapeutisk allianse og en felles forståelse med pasient og pårørende om hva som forårsaker og vedlikeholder anfallene.

I noen særlig terapiresistente tilfeller kan det være behov for langvarig behandling. Slik behandling må foregå lokalt.

\section{Prognose}

Sammenlignet med voksne med psykogene ikke-epileptiske anfall er utsiktene til anfallsfrihet bedre blant barn og unge med slike anfall, kanskje fordi det hos disse er lettere å identifisere en ytre årsak (6). Rundt 70-80\% av barna blir kvitt anfallene $(11,13)$.

\section{Morten I. Lossius (f. 1962)}

er dr. med., spesialist i nevrologi og overlege. Han er leder av forskningsgruppen.

Forfatter har fylt ut ICMJE-skjemaet og oppgir ingen interessekonflikter.

\section{Antonia Villagran (f. 1976)}

er overlege og spesialist i nevrologi, med spesialkompetanse innen epileptologi.

Forfatter har fylt ut ICMJE-skjemaet og oppgir ingen interessekonflikter.

\section{Hilde N. Karterud (f. 1956)}

er sykepleier og for tiden ph.d-student. Forfatter har fylt ut ICMJE-skjemaet og oppgir ingen interessekonflikter.

\section{Oliver Henning (f. 1965)}

er overlege, spesialist i nevrologi og i psykiatri og har spesialkompetanse innen epileptologi. Forfatter har fylt ut ICMJE-skjemaet og oppgir ingen interessekonflikter.

\section{Karl 0. Nakken (f. 1945)}

er overlege, dr. med. og spesialist i nevrologi. Han har spesialkompetanse innen epileptologi og er medisinsk fagsjef.

Forfatter har fylt ut ICMJE-skjemaet og oppgir ingen interessekonflikter.

\section{Litteratur}

1. Lund C, Haraldsen I, Lossius MI et al. Psykogene ikke-epileptiske anfall. Tidsskr Nor Legeforen 2009; 129: 2348-51

2. Tuft M, Karterud HN, Villagran A et al. Behandling ved psykogene ikke-epileptiske anfall. Tidsskr Nor Legeforen 2015; 135: 1449-51

3. Wyllie E, Glazer JP, Benbadis S et al. Psychiatric features of children and adolescents with pseudoseizures. Arch Pediatr Adolesc Med 1999: 153: 244-8.

4. Plioplys S, Doss J, Siddarth P et al. A multisite controlled study of risk factors in pediatric psychogenic nonepileptic seizures. Epilepsia 2014; 55: $1739-47$.

5. Kim SH, Kim H, Lim BC et al. Paroxysmal nonepileptic events in pediatric patients confirmed by long-term video-EEG monitoring-Sing le tertiary center review of 143 patients. Epilepsy Behav 2012 24: $336-40$.

6. Irwin K, Edwards M, Robinson R. Psychogenic nonepileptic seizures: management and prognosis, Arch Dis Child 2000; 82: 474-8
7. Vincentiis S, Valente KD, Thomé-Souza S et al. Risk factors for psychogenic nonepileptic seizures in children and adolescents with epilepsy. Epilepsy Behav 2006; 8: 294-8

8. Patel H, Scott E, Dunn D et al. Nonepileptic seizures in children. Epilepsia 2007; 48: 2086-92.

9. Alessi R, Vincentiis S, Rzezak P et al. Semiology of psychogenic nonepileptic seizures: age-related differences. Epilepsy Behav 2013; 27: 292-5.

10. Dhiman V, Sinha S, Rawat VS et al. Children with psychogenic non-epileptic seizures (PNES): a detailed semiologic analysis and modified new classification. Brain Dev 2014; 36: 287-93.

11. Wyllie E, Friedman D, Lüders $\mathrm{H}$ et al. Outcome of psychogenic seizures in children and adolescents compared with adults. Neurology 1991; 41: 742-4.

12. Szabó L, Siegler Z, Zubek L et al. A detailed semiologic analysis of childhood psychogenic nonepilep tic seizures. Epilepsia 2012; 53: 565-70.

13. Rawat VS, Dhiman V, Sinha S et al. Co-morbidities and outcome of childhood psychogenic non-epileptic seizures-an observational study. Seizure 2015; 25: 95-8.

14. Reuber M, Fernández G, Bauer J et al. Diagnostic delay in psychogenic nonepileptic seizures. Neurology 2002: 58: 493-5.

15. Pakalnis A, Paolicchi J. Frequency of secondary conversion symptoms in children with psychogenic nonepileptic seizures. Epilepsy Behav 2003; 4: 753-6.

16. Uldall P, Alving J, Hansen LK et al. The misdiagnosis of epilepsy in children admitted to a tertiary epilepsy centre with paroxysmal events. Arch Dis Child 2006; 91: 219-21.

17. Kutluay E, Selwa L, Minecan D et al. Nonepileptic paroxysmal events in a pediatric population. Epilepsy Behav 2010; 17: 272-5.

18. Kotagal P, Costa M, Wyllie E et al. Paroxysmal nonepileptic events in children and adolescents. Pediatrics 2002; 110: e46.

19. Seneviratne U, Reutens D, D'Souza W. Stereotypy of psychogenic nonepileptic seizures: insights from video-EEG monitoring. Epilepsia 2010; 51 1159-68.

20. Hubsch C. Baumann C. Hingray C et al. Clinical classification of psychogenic non-epileptic seizures based on video-EEG analysis and automatic clustering. J Neurol Neurosurg Psychiatry 2011; 82: $955-60$

21. Morgan LA, Buchhalter J. Psychogenic paroxysmal nonepileptic events in children: a review. Pediatr Neurol 2015; 53: 13-22

22. Sawchuk T, Buchhalter J. Psychogenic nonepileptic seizures in children - Psychological presentation, treatment, and short-term outcomes. Epilepsy Behav 2015; 52 (Pt A): 49-56.

23. Beghi M, Cornaggia I, Magaudda A et al. Childhood trauma and psychogenic nonepileptic seizures: A review of findings with speculations on the underlying mechanisms. Epilepsy Behav 2015; 52 (Pt A) 169-73.

24. Wichaidit BT, Østergaard JR, Rask CU. Diagnostic practice of psychogenic nonepileptic seizures (PNES) in the pediatric setting. Epilepsia 2015: 56: 58-65.

25. Wichaidit BT, Rask CU, Østergaard JR. Diagnosing functional seizures in children and adolescents. Ugeskr Laeger 2014; 176: 1070-5.

26. Provini F, Plazzi G, Tinuper P et al. Nocturnal frontal lobe epilepsy. A clinical and polygraphic overview of 100 consecutive cases. Brain 1999; 122: 1017-31.

27. LaFrance WC Jr, Reuber M, Goldstein LH. Management of psychogenic nonepileptic seizures. Epilepsia 2013. 54 (suppl 1): 53-67.

28. Karterud HN, Haavet OR, Risør MB. Social participation in young people with nonepileptic seizures (NES): A qualitative study of managing legitimacy in everyday life. Epilepsy Behav 2016; 57 (Pt A): 23-8.

29. Karterud HN, Risør MB, Haavet OR. The impact of conveying the diagnosis when using a biopsychosocial approach: A qualitative study among adolescents and young adults with NES (non-epileptic seizures). Seizure 2015; 24: 107-13. 